\title{
Design Optimization of HANARO Irradiation Capsule for Long-Term Irradiation Testing
}

\author{
Kee Nam Choo (i), Man Soon Cho ${ }^{(D)}$, Seong Woo Yang $(\mathbb{D}$, \\ Byung Hyuk Jun, and Myong Seop Kim
}

Department of HANARO Operation and Utilization, Korea Atomic Energy Research Institute, 111 Daedeok-daero, 989 Beon-gil, Yuseong-gu, Daejeon 34057, Republic of Korea

Correspondence should be addressed to Kee Nam Choo; knchoo@kaeri.re.kr

Received 10 November 2017; Accepted 8 January 2018; Published 8 February 2018

Academic Editor: Arkady Serikov

Copyright (C) 2018 Kee Nam Choo et al. This is an open access article distributed under the Creative Commons Attribution License, which permits unrestricted use, distribution, and reproduction in any medium, provided the original work is properly cited.

As HANARO has been recently required to support new R\&D relevant to future nuclear systems requiring much higher neutron fluence, two types of bottom rod tip of the capsule were preliminarily prepared. The first one is a conventional design made of STS304 and welded using a tungsten inert gas (TIG) welding method. The other is a new design made of STS316L and welded using electron beam (EB) welding to strengthen the fatigue property of the rod tip. During the out-pile testing, they failed after 40 and 203 days, respectively. The fracture surfaces were examined using microscopes and the maximal applied stresses were estimated. The combination of these stresses was proved to be sufficient to cause a fatigue failure of the rod tip of the capsule. Based on the failure analysis, an optimized design of the rod tip of the capsule was made for long-term irradiation testing. It was designed to improve the welding and fatigue properties, to decrease the applied stress on the rod tip, and to fundamentally eliminate the effect of residual stress due to welding. The newly designed capsule was safely out-pile-tested up to 450 days and will be utilized for HANARO irradiation testing.

\section{Introduction}

The High-Flux Advanced Neutron Application Reactor (HANARO), located at the Korea Atomic Energy Research Institute (KAERI) in Korea, has been operating as a platform for basic nuclear research in Korea, and the functions of its systems have been continuously improved since its first criticality in February 1995 [1]. Both the general design features and detailed information about this reactor are available on the HANARO homepage (http://hanaro.kaeri.re.kr). To support the national research and development programs on nuclear reactors and nuclear fuel cycle technology in Korea, irradiation capsules have been developed and actively utilized for the irradiation tests requested by numerous users [2-6]. The capsule technology was basically developed for irradiation testing under a commercial reactor operation environment. Most irradiation testing using capsules has been performed at around $300^{\circ} \mathrm{C}$ within four reactor operation cycles (about 100 days) at HANARO.
Based on the accumulated experience as well as the sophisticated requirements of users, HANARO has recently been required to support national $R \& D$ projects relevant to future nuclear systems. As future nuclear systems are demanding higher neutron fluence irradiation than present nuclear power plants [7], it is necessary to verify the integrity of the irradiation capsule for longer irradiation testing at HANARO. However, as the irradiation capsule is exposed to a very high pressure coolant flow during irradiation testing, it has been suspected to be vulnerable to vibrationinduced fatigue cracking. Therefore, HANARO instrumented capsules have been limited to irradiation of within four reactor operation cycles equivalent to $1.5 \mathrm{dpa}$. Several design improvements of the capsules were suggested and partially demonstrated for the irradiation at HANARO at up to eight reactor operation cycles equivalent to $3 \mathrm{dpa}$ [6].

In this paper, limiting factors for longer irradiation testing of the irradiation capsule were discussed and different designs of the capsule were out-pile-tested. It is hoped that the present 
study will provide design improvements of the capsule for longer irradiation testing at HANARO.

\section{HANARO and Irradiation Facilities}

HANARO, a $30 \mathrm{MW}$ open-pool type multipurpose research reactor, has been operated as a platform for nuclear research in Korea since commencing its operation in 1995. There are several vertical test holes for irradiation testing of nuclear fuels and materials. The characteristics of the reactor test holes at HANARO were previously described elsewhere $[4,5]$.

Various neutron irradiation facilities such as rabbit irradiation facilities, loop facilities, and capsule irradiation facilities for irradiation tests of nuclear materials, fuels, and radioisotope products have been developed at HANARO [2, $3]$. Among the irradiation facilities, the irradiation capsules have been most actively used for the irradiation of nuclear materials. Figure 1 shows a standard irradiation capsule and an installed capsule in the reactor core. Because of the up stream of the coolant in the reactor, the irradiation capsule is fixed or supported at four points, which are the bottom and top of the main body, the top of the reactor chimney, and the capsule location of the robot arm. After locking the capsule in a test hole, the instrumented capsule is fixed by a bracket and robotic arm support systems. Two sets of cantilever type robotic arm systems for the CT and IR2 test holes were installed at the location of the platform level of the reactor, which is $5.5 \mathrm{~m}$ in height from the bottom of the capsule; however, the bracket is temporarily installed at the top of the reactor chimney for capsule irradiation testing. At the junction box system, heaters and thermocouples can be easily connected to, and separated from, the capsule controlling system before or after an irradiation test. The capsule temperature control system consists of three subsystems: a vacuum control system, a multistage heater control system, and a man-machine interface system.

A typical HANARO irradiation material capsule consists of three main parts that are connected to each other: a protection tube $(5 \mathrm{~m})$, a guide tube $(9.5 \mathrm{~m})$, and the capsule's main body, as shown in Figure 1(a). The main body including the specimens and instruments is a cylindrical shaped tube of $60 \mathrm{~mm}$ diameter and $1170 \mathrm{~mm}$ length. The main body has five stages with independent microelectric heaters, thermocouples, and neutron fluence monitors to measure the temperature and neutron fluences of the specimens, respectively. Heaters and thermocouples are connected to a capsule temperature controlling system through a guide tube and a junction box system. A friction welded tube using STS304 and Al1050 alloys is introduced to prevent coolant leakage into the capsule during the capsule cutting process after irradiation.

Irradiation technology at HANARO was basically developed for irradiation testing under a commercial reactor operation environment. Table 1 summarizes the current status of irradiation technology at HANARO compared with the advanced foreign technology.

\section{Long-Term Irradiation Testing at HANARO}

As the HANARO irradiation capsules were developed for irradiation testing under a commercial reactor operation environment, irradiation testing using an instrumented capsule has been performed within four reactor operation cycles (about 100 days) at HANARO. HANARO has been recently required to support new $R \& D$ relevant to future nuclear systems such as a VHTR, SFR, and fusion reactors requiring much higher neutron fluence. To scope the user requirements for a higher neutron fluence, several efforts have been applied at HANARO. First, a long-term irradiation capsule technology of up to 3 dpa was recently developed and applied [6]. $3 \mathrm{dpa}$ is equivalent to irradiation testing for eight cycles at HANARO. The long-term irradiation capsule technology was scheduled to extend its capability up to $5 \mathrm{dpa}$ for the irradiation of materials of future nuclear systems. The improvement of the capsule technology was based on a safety analysis and a design optimization of the irradiation capsule.

To evaluate the performance and safety of the newly designed capsules, the capsules were out-pile-tested in the single channel out-pile test loop. The vibration behaviors of the capsules in the loop were also measured using a laser vibrometer, as shown in Figure 2. Out-pile testing is usually performed under $110 \%$ accelerated conditions of a reactor coolant flow amount in the single channel out-pile test loop to shorten the testing period.

3.1. Susceptibility of the Capsule. As the irradiation capsule is exposed to a very high pressure coolant flow of $19.6 \mathrm{~kg} / \mathrm{s}$ during irradiation testing, the bottom rod tip of the capsule has been suspected to be vulnerable to vibration-induced fatigue failure. Therefore, the integrity of the irradiation capsules should be fully checked before long-term irradiation testing at HANARO.

Two types of bottom part of the capsule were prepared based on the standard capsule design for long-term irradiation testing, as shown in Figure 3. One is a conventional design having a rod tip made of STS304 and welded to a bottom guide by a tungsten inert gas (TIG) welding method. For the other, the material of the rod tip was STS316L, and the welding method was electron beam (EB) welding to strengthen the fatigue property of the rod tip. The weld depth of the rod tip was required to be at least $4 \mathrm{~mm}$. Although a multipass weld method was applied on the TIG welding for adequate weld depth, a single-pass weld method was applied on the EB welding. STS316L is known to have superior properties compared with STS304 in terms of welding [8]. Moreover, EB welding is considered to have a narrow weld area, resulting in a less harmful distribution of residual stress in the weld area [9]. The soundness of the EB welded parts was tested using mock-up test specimens, as shown in Figure 4(a). The EB welded part was found to have similar strength to the matrix and to have $6.5 \mathrm{~mm}$ weld depth, as shown in Figures 4(b) and 5, respectively. During the out-pile testing, the two types of rod tips of the capsules failed after 40 and 203 days, respectively, under the $110 \%$ accelerated conditions of a normal reactor coolant flow. Figure 6 shows failed parts of the capsule that occurred during out-pile testing.

3.2. Fractographic Failure Analysis of the Rod Tip of the Capsule. Figure 7 shows the lengths of the failed rod tips 


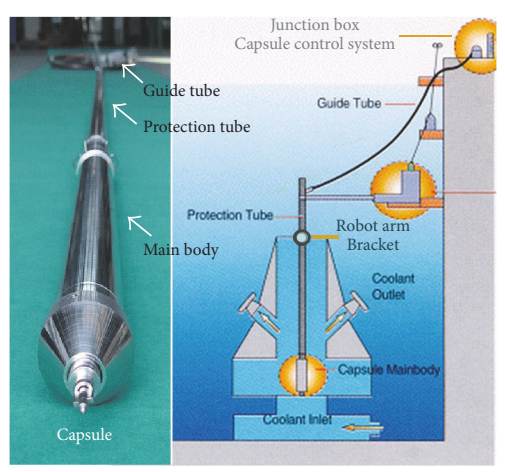

(a)

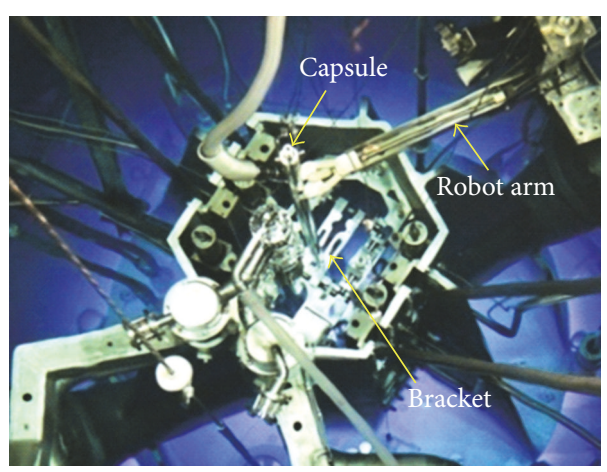

(b)

FIGURE 1: HANARO irradiation capsule systems: (a) a standard irradiation capsule and (b) an irradiation capsule system installed in the reactor core.

TABLE 1: Status of irradiation technology of HANARO.

\begin{tabular}{|c|c|c|c|c|}
\hline Fields & KAERI & Worldwide & $\mathrm{R} \& \mathrm{D}$ target & Remarks \\
\hline \multirow{2}{*}{ Temp. $\left({ }^{\circ} \mathrm{C}\right)$} & $50 \sim 700$ & $50 \sim 1,400$ & $50 \sim 1,300$ & \\
\hline & \pm 10 & \pm 3 & \pm 5 & Accuracy \\
\hline \multirow{2}{*}{ Fluence accuracy } & - & $\pm 20 \%$ & $\pm 20 \%$ & Thermal \\
\hline & $\pm 20 \%$ & $\pm 10 \%$ & $\pm 10 \%$ & Fast \\
\hline $\begin{array}{l}\text { Flux } \\
\left(\mathrm{n} / \mathrm{cm}^{2} \cdot \mathrm{sec}\right)\end{array}$ & $6 \times 10^{12} \sim 1.4 \times 10^{14}$ & No limit & $1.5 \times 10^{9} \sim 1.4 \times 10^{14}$ & $E>1 \mathrm{MeV}$ \\
\hline Irradiation cycle (days) & $\begin{array}{c}8 \text { cycles } \\
(\sim 200 \text { days })\end{array}$ & No limit & $\begin{array}{c}30 \text { cycles } \\
(\sim 750 \text { days })\end{array}$ & \\
\hline $\begin{array}{l}\text { Fluence }\left(\mathrm{n} / \mathrm{cm}^{2}\right) \\
(\mathrm{dpa})\end{array}$ & $\begin{array}{c}1.9 \times 10^{21} \\
(3.0)\end{array}$ & No limit & $\begin{array}{c}6.5 \times 10^{21} \\
(10.0)\end{array}$ & $E>1 \mathrm{MeV}$ \\
\hline
\end{tabular}

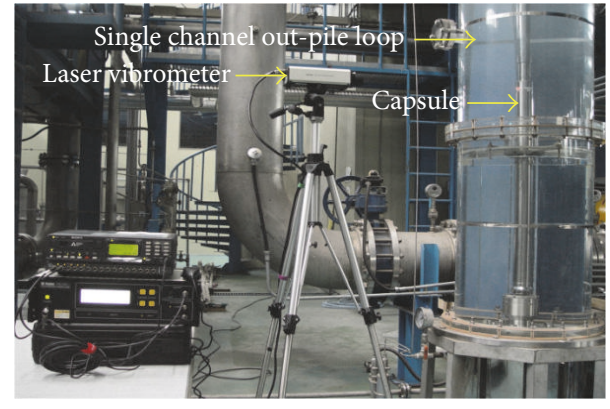

FIGURE 2: Measuring the vibration of a capsule installed in the single channel out-pile test loop.

compared to an original one of the capsule. Considering that the welding depth of the rod tips was controlled to be about $\sim 6.5 \mathrm{~mm}$, the failed positions of the rod tips seem to be related to the welded parts. Figure 8 shows the optical fracture surfaces of the rod tips. The surfaces show the typical appearances of fatigue fracture found in the literature $[10,11]$. In the rod tip of the TIG welded STS304, more than three cracks seemed to be initiated from the surface and then almost entirely fractured in brittle mode. Much more cracks that initiated near the surface propagated toward the center, and finally a ductile fracture occurred in the rod tip of the
EB welded STS316L. Figure 9 shows a side view and SEM of the fractured surface of the rod tip of the EB welded STS316L depicting crack initiation sites. The weld pits of the rod tip seem to act as stress concentration sites for crack initiation. It is known that the fatigue strength of stainless steel can be lowered to one-half the value by a pit [12]. Figure 10 shows microstructures of the cross sections taken from the half-sectioned failed rod tips. Although the cracks propagated through welds in the TIG welded rod tip, the cracks propagated through the as-received matrix in the EB welded rod tip.

Considering the vibration of the capsule induced by a coolant flow [6] and the typical failure appearances of the rod tips, these cracks seemed to initiate and progress through vibration-induced fatigue cracking.

3.3. Stress Analysis of the Rod Tip of the Capsule. As the rod tip of the capsule seems to be susceptible to stressinduced fatigue cracking, the capsule should be safe against all possible stresses applied to the capsule parts during the irradiation testing. The applied stresses on the rod tip can be classified into stresses by the designed bottom spring, by the upward flowing coolant, by the capsule vibration, and by the residual welding stress.

As shown in Figure 3, a bottom spring is located in the capsule design. The spring is at a compressed condition of 


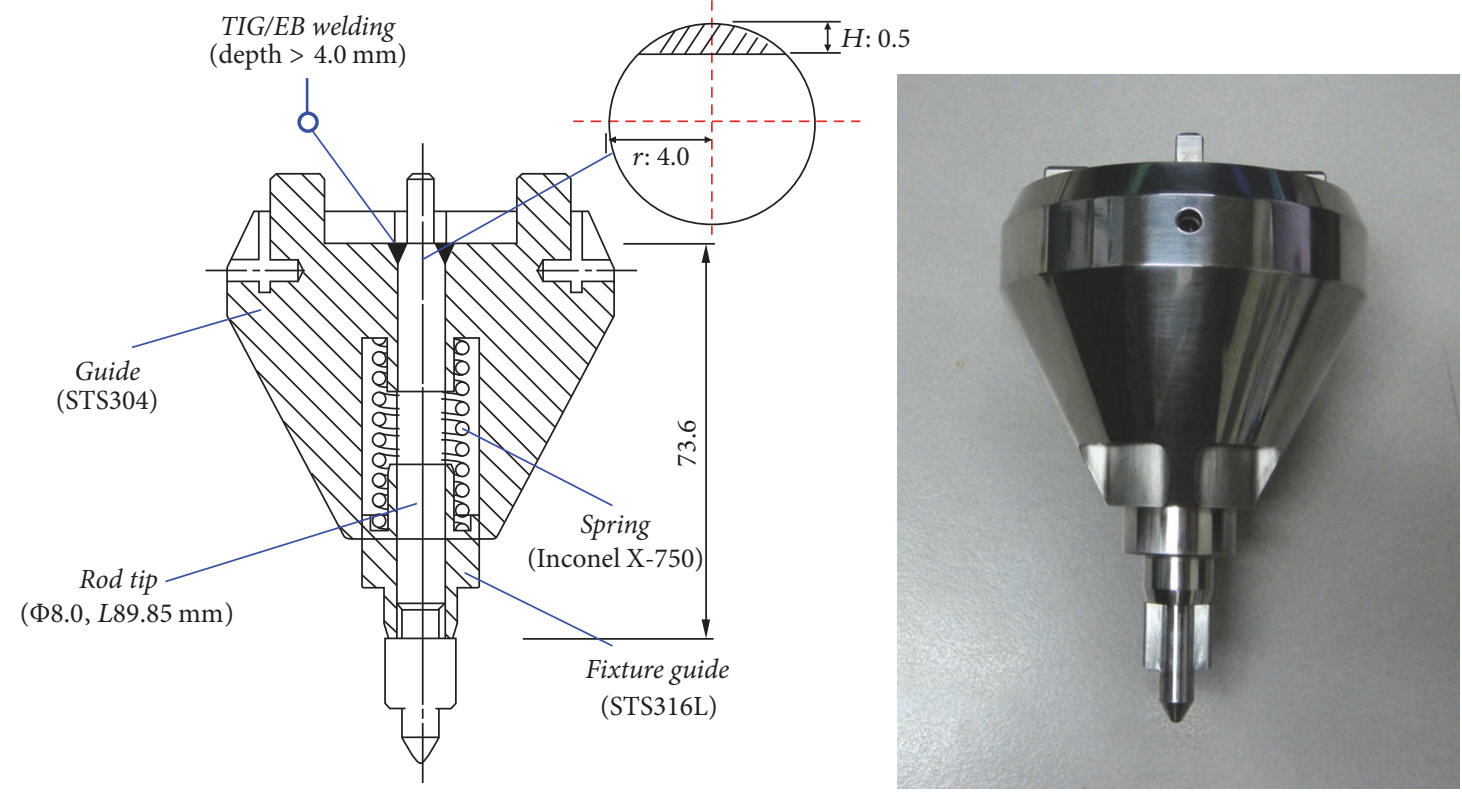

FIgURE 3: The standard design of the capsule bottom part.

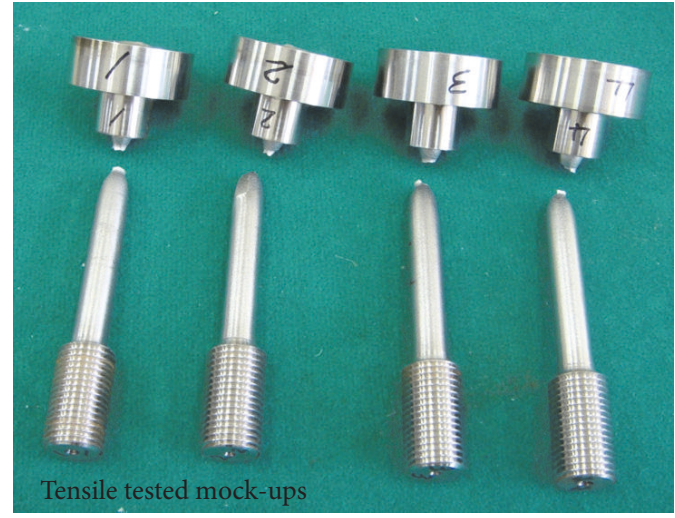

(a)

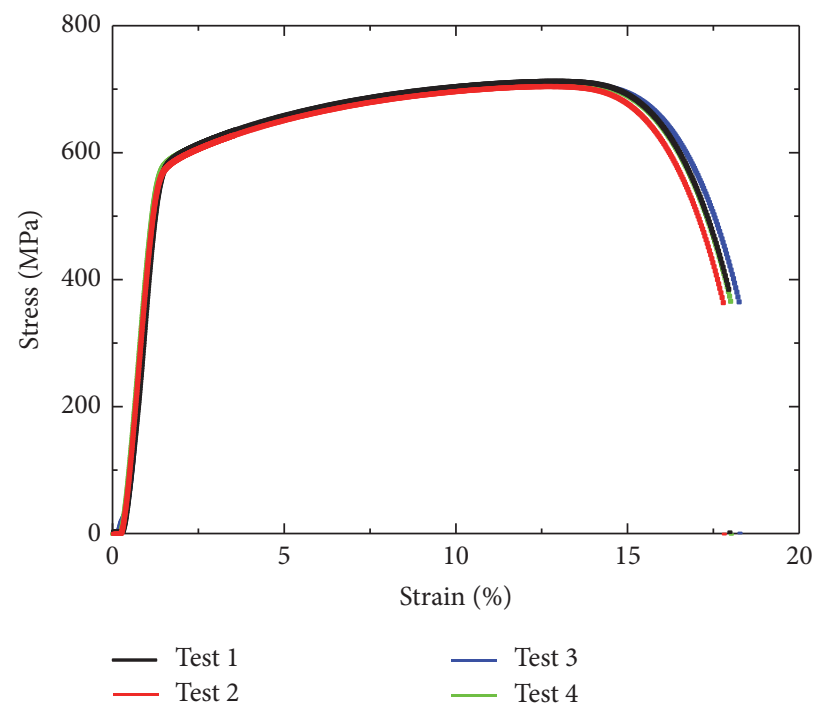

(b)

FIGURE 4: Tensile testing using mock-ups of the EB welded capsule bottom parts: (a) tensile tested mock-ups and (b) stress-strain curves of the mock-ups.

$27 \mathrm{kgf}$ and was evaluated to provide a tensile stress of $5.4 \mathrm{MPa}$ on the rod tip. The stress seems to be negligible when compared with the fatigue strength of the rod tip of $300 \mathrm{MPa}$ [13].

As the loaded capsule is exposed to a forced upward coolant flow of $19.6 \mathrm{~kg} / \mathrm{s}$ during irradiation, the capsule receives tensile stress by the coolant flow and bending stress by coolant flow-induced vibration. The stress on the rod tip of the capsule by the upward coolant flow was evaluated using the ANSYS code. The highest stress of 132.9 MPa was obtained at an $11.5 \mathrm{~mm}$ position from the end of the rod tip under $110 \%$ coolant conditions, as shown in Figure 11.
The vibration characteristics of the optimized capsule were measured using a laser vibrometer. The out-pile test conditions of a $110 \%$ reactor coolant flow amount resulted in a coolant flow-induced vibration having a frequency of about $11 \mathrm{~Hz}$ and complex vibration amplitude [6]. The obtained root mean square (RMS) of vibration amplitude of $120.42 \mu \mathrm{m}$ at a point $1.42 \mathrm{~m}$ above the rod tip was evaluated to have the highest stress of $161 \mathrm{MPa}$ at a $15 \mathrm{~mm}$ position from the end of the rod tip using the ANSYS code, as shown in Figure 12.

The rod tip of the capsule is welded to the bottom guide of the capsule, resulting in a harmful distribution of residual 


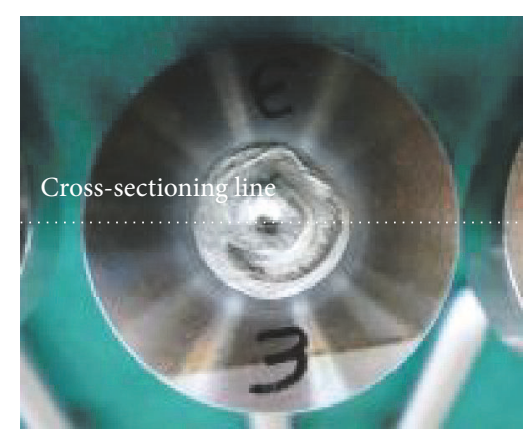

(a)

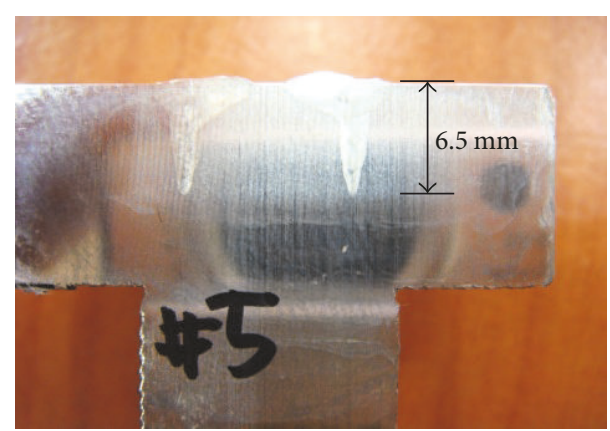

(b)

FIGURE 5: Cross-sectioning of a mock-up of the EB welded capsule bottom parts: (a) EB welded mock-up of the capsule bottom part and (b) cross-sectioned surface showing $6.5 \mathrm{~mm}$ weld depth.

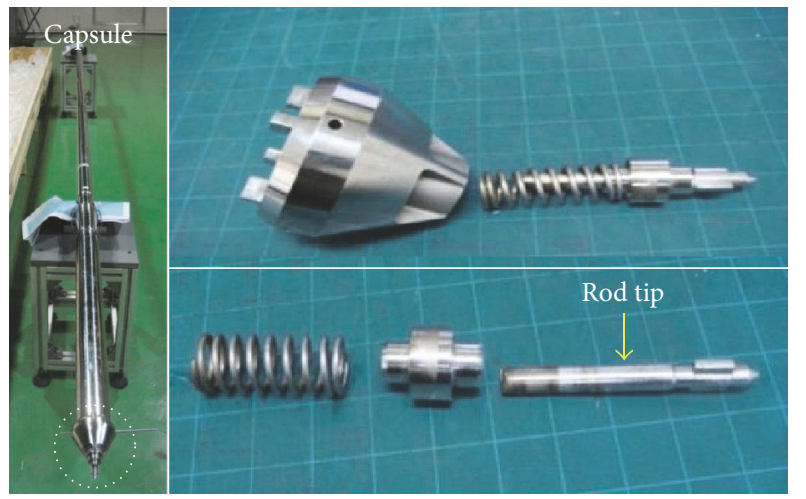

FIGURE 6: Failed capsule bottom parts during out-pile testing in the single channel out-pile test facility.

stress in the weld area. It is known that residual stress can reach up to about $300 \mathrm{MPa}$, irrespective of the welding method [9]. $300 \mathrm{MPa}$ is the known fatigue strength of the stainless steel of the rod tip [13].

The maximal applied stresses on the rod tip by the designed bottom spring, by the upward flowing coolant, and by the capsule vibration were estimated as $5.4 \mathrm{MPa}, 132.9 \mathrm{MPa}$, and $161 \mathrm{MPa}$, respectively. These stresses do not exceed the known fatigue strength of stainless steel ( $300 \mathrm{MPa})$. Residual stress by welding that is known to occur at up to about $300 \mathrm{MPa}$ is another possible stress for failure. Therefore, the combination of these stresses can be enough to cause a fatigue failure of the rod tip of the capsule. The earlier failure of the TIG welded STS304 can be explained by fast crack propagation through the weld owing to the residual stress of the welding.

\section{Design Optimization for Longer Irradiation Testing}

Based on the failure analysis, a new design of the rod tip of the capsule was made for long-term irradiation testing of up to $5 \mathrm{dpa}$, as shown in Figure 13. Cold-worked STS316L having

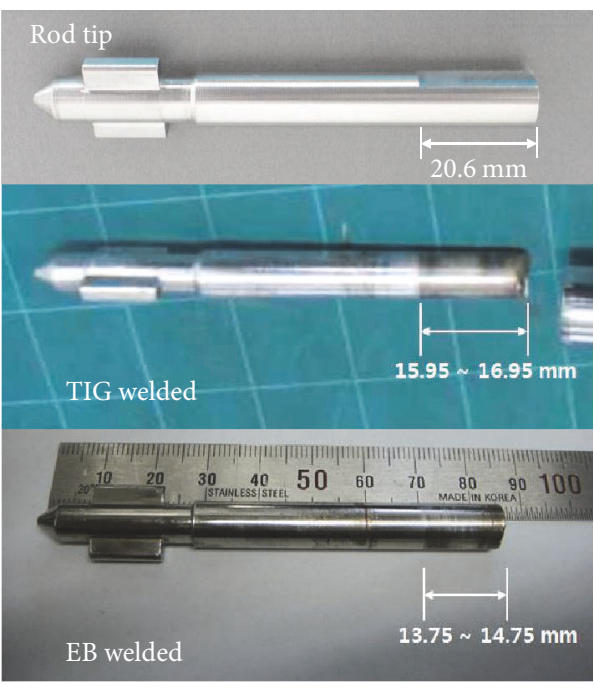

FIGURE 7: Comparison of the failed rod tip of the capsule.

a strength of $696 \mathrm{MPa}$ was selected as a rod tip material owing to its $10 \%$ higher strength than the previous STS316L and its superior properties over STS304 in terms of welding. The fatigue strength of a material is known [13] to be about half the value of strength of the material. EB welding was determined to have a narrower weld area than previous TIG welding, resulting in a less harmful distribution of residual stress in the weld area. To decrease the applied stress on the rod tip, the diameter of the rod tip was increased from $8.0 \mathrm{~mm}$ to $9.0 \mathrm{~mm}$, and the height of the tapered part of the rod tip decreased from $0.5 \mathrm{~mm}$ to $0.2 \mathrm{~mm}$. This results in a decrease of $22.6 \%$ of the applied stress under the same conditions. The gap (gap 1 in Figure 13) between the rod tip and the bottom guide and the gap (gap 2) between the fixture guide and the bottom guide were decreased from 0.05 to $0.025 \mathrm{~mm}$ and from $0.15 \mathrm{~mm}$ to $0.05 \mathrm{~mm}$, respectively, to suppress the applied stress by constraining the vibration of the rod tip. The length of the rod tip was increased by $7 \mathrm{~mm}$ to position the weld part of the rod tip above the stressed position to eliminate the effects of residual stress due to welding. 


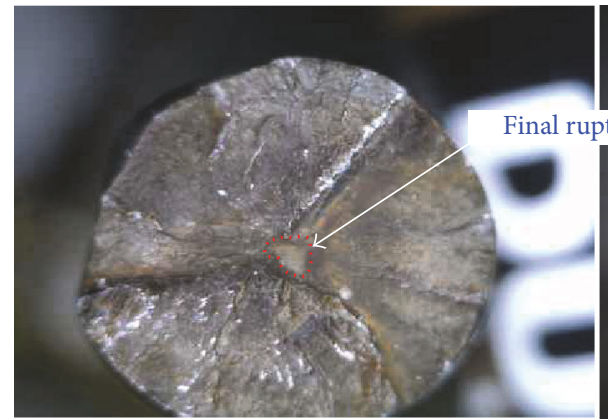

(a)

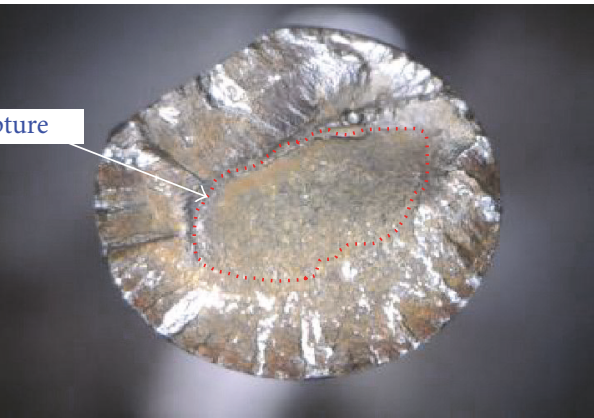

(b)

FIGURE 8: Fractured surface of the rod tips: (a) the TIG welded STS304 and (b) the EB welded STS316L.

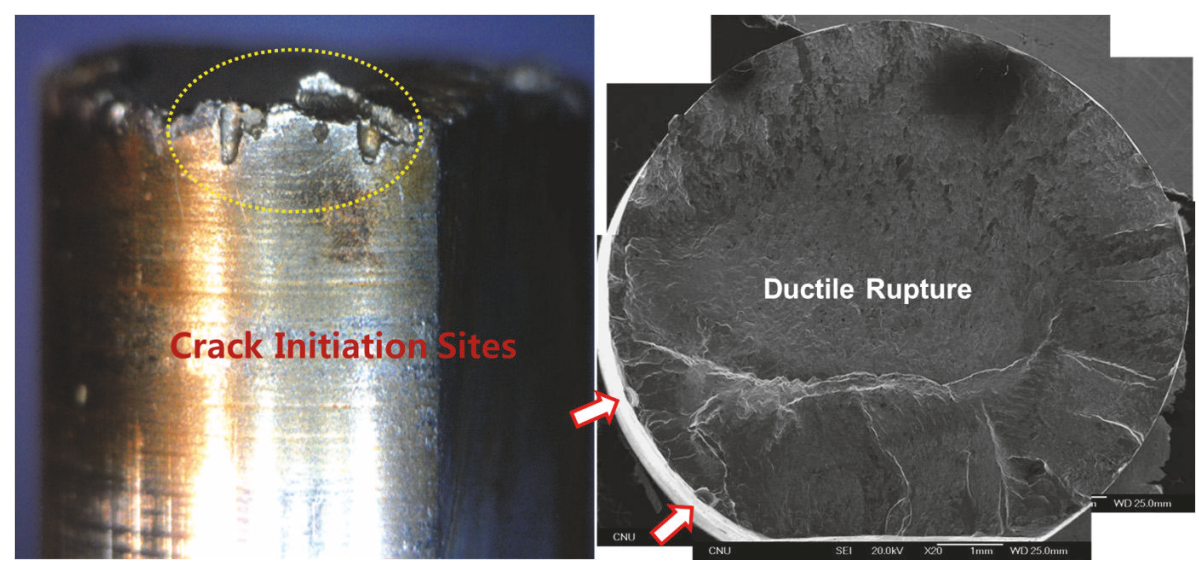

FIGURE 9: Side view and SEM of a fractured surface of the rod tip of the EB welded STS316L depicting crack initiation sites.

The safety of the new capsule should be fully checked before irradiation testing. The out-pile performance was determined and endurance testing was performed in the single channel out-pile test loop. Out-pile testing was also performed under $110 \%$ accelerated conditions of a reactor coolant flow amount to shorten the testing period. The newly designed capsule was safely out-pile-tested for up to 450 days equivalent to $5 \mathrm{dpa}$ irradiation in the reactor and will be utilized for HANARO irradiation testing.

\section{Further Works}

At up to $5 \mathrm{dpa}$ of irradiation, improvements of the capsule technology have been performed based on a design optimization of the irradiation capsule. However, for a higher neutron fluence exceeding $5 \mathrm{dpa}$, new capsule technologies including a new concept capsule, flux boosting, reirradiation, and reinstrumentation are under planning at HANARO. This will scope the user requirements for the national R\&D on next-generation nuclear power plants.

\section{Conclusion}

To support new R\&D relevant to future nuclear systems requiring much higher neutron fluence, the integrity of the capsule for longer testing was evaluated, and different capsule designs were out-pile-tested. Two types of bottom rod tip of the capsule were preliminarily designed for long-term irradiation testing. One is a conventional design made of STS304 and welded using a tungsten inert gas (TIG) welding method. For the other, the material of the rod tip was STS316L, and the welding method was electron beam (EB) welding to strengthen the fatigue property of the rod tip. During the out-pile testing, two types of rod tips of the capsules failed after 40 and 203 days, respectively, under the $110 \%$ accelerated conditions of a normal reactor coolant flow. Considering the vibration of the capsule induced by the coolant flow and the typical failure appearances of the rod tips, it was suggested that several cracks were initiated at the surface and progressed toward the center through vibrationinduced fatigue cracking. The maximal applied stresses on the rod tip by the designed bottom spring, the upward flowing coolant, the capsule vibration, and the residual stress from welding were estimated as $5.4 \mathrm{MPa}, 132.9 \mathrm{MPa}, 161 \mathrm{MPa}$, and $300 \mathrm{MPa}$, respectively. The combination of these stresses was proved to be enough to cause fatigue failure of the rod tip of the capsule. Based on the failure analysis, a new design of the rod tip of the capsule was made for long-term irradiation testing of up to $5 \mathrm{dpa}$. High-strength STS316L was selected as a rod tip material owing to its superior properties over STS304 in terms of welding and for higher fatigue strength. EB welding was determined to have a narrower weld area than 


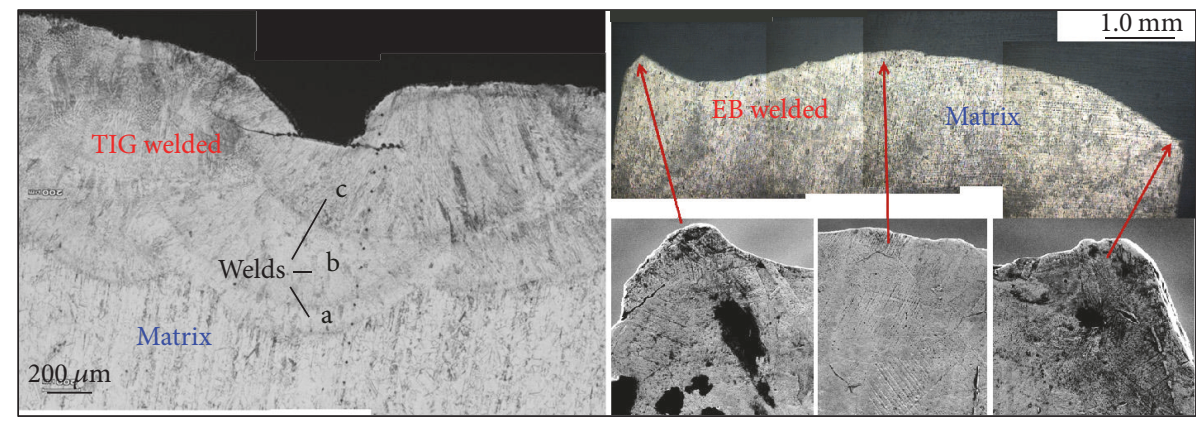

FIGURE 10: Microstructures of cross sections taken from the half-sectioned failure rods.

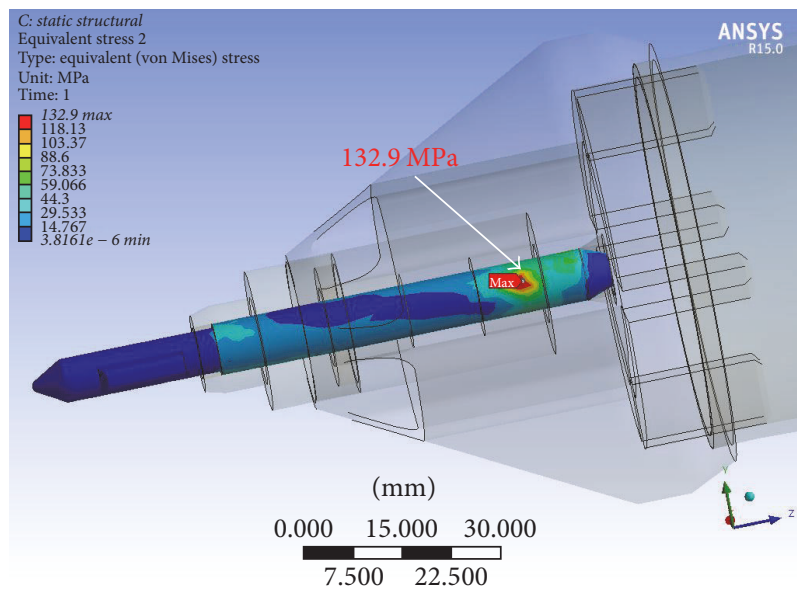

FIgURe 11: Applied stress on the rod tip by coolant flow.

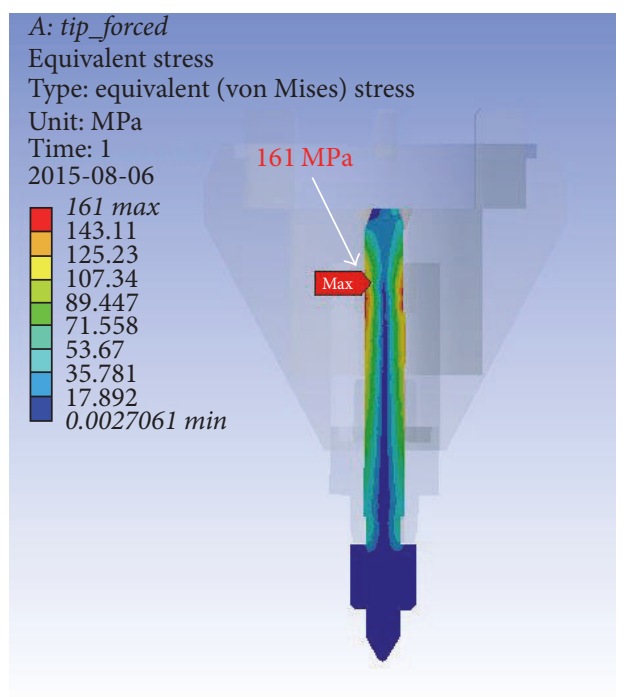

Figure 12: Applied stress on the rod tip by capsule vibration.

previous TIG welding, resulting in a less harmful distribution of residual stress in the weld area. The dimensions of the bottom parts were optimized to suppress the applied stress on the rod tip and to fundamentally eliminate the effects of residual stress due to welding. The newly designed capsule

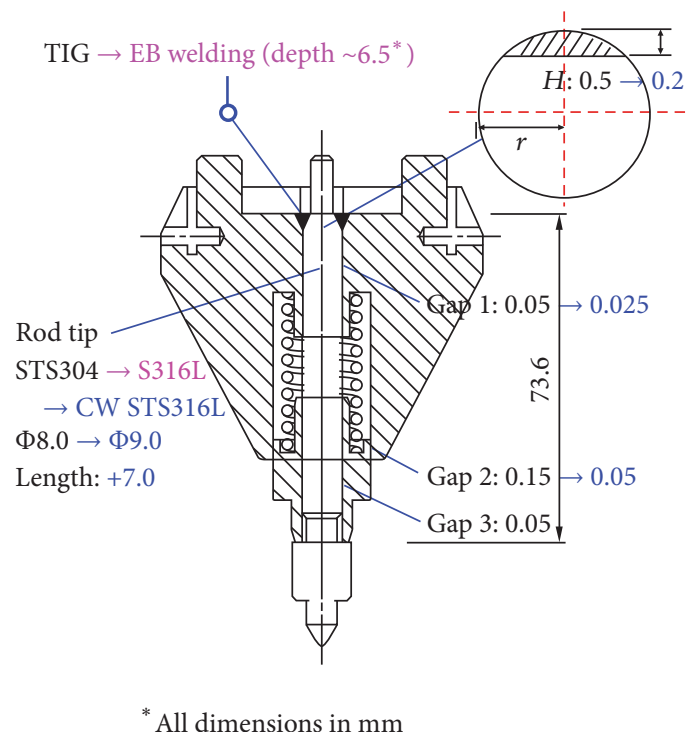

FIgURE 13: The improved design of the capsule bottom part for longterm irradiation testing.

was safely out-pile-tested for up to 450 days equivalent to 5 dpa of irradiation in the reactor and will be utilized for HANARO irradiation testing.

\section{Conflicts of Interest}

The authors declare that they have no conflicts of interest.

\section{Acknowledgments}

This work was supported by the National Research Foundation of Korea (NRF) grant funded by the Korean Government (MSIT) (NRF-2013M2A8A1035822).

\section{References}

[1] C.-O. Choi, H.-R. Kim, K.-H. Lee, C.-S. Lee, and J.-M. Sohn, "Present situations and perspectives on the advanced utilization of HANARO," Physica B: Condensed Matter, vol. 311, no. 1-2, pp. 34-39, 2002. 
[2] K.-N. Choo and B.-G. Kim, "Development and application of irradiation technology in HANARO," Solid State Phenomena, vol. 135, pp. 93-98, 2008.

[3] K. N. Choo, "Material irradiation at HANARO, Korea: research reactor application for materials under high neutron fluence," IAEA-TECDOC-1659, 2011.

[4] K. N. Choo, "Contribution of HANARO irradiation technologies to national nuclear R \& D," Nuclear Engineering and Technology, vol. 46, no. 4, pp. 501-512, 2014.

[5] M. S. Cho, K. N. Choo, and S. W. Yang, "Material irradiation technology using capsules at HANARO," Nuclear Technology, vol. 193, no. 2, pp. 330-339, 2016.

[6] K. N. Choo, M. S. Cho, S. W. Yang, B. H. Jun, and M. S. Kim, "Development of a low-Temperature irradiation capsule for research reactor materials at HANARO," Nuclear Technology, vol. 195, no. 2, pp. 213-221, 2016.

[7] K. L. Murty and I. Charit, "Structural materials for Gen-IV nuclear reactors: Challenges and opportunities," Journal of Nuclear Materials, vol. 383, no. 1-2, pp. 189-195, 2008.

[8] J. M. Keisler, O. K. Chopra, and W. J. Shack, "Statistical models for estimating fatigue strain-life behavior of pressure boundary materials in light water reactor enviroments," Nuclear Engineering and Design, vol. 167, no. 2, pp. 129-154, 1996.

[9] J. Sun, X. Liu, Y. Tong, and D. Deng, "A comparative study on welding temperature fields, residual stress distributions and deformations induced by laser beam welding and $\mathrm{CO}_{2}$ gas arc welding," Materials and Corrosion, vol. 63, pp. 519-530, 2014.

[10] G. F. Vander Voort, Macroscopic Examination Procedures for Failure Analysis, Metallography in Failure Analysis, J. L. McCALL and P. M. French, Eds., Plenum Press, NY, USA, 1978.

[11] R. Avilés, J. Albizuri, A. Rodríguez, and L. N. López De Lacalle, "Influence of low-plasticity ball burnishing on the high-cycle fatigue strength of medium carbon AISI 1045 steel," International Journal of Fatigue, vol. 55, pp. 230-244, 2013.

[12] K. Masaki, Y. Ochi, and T. Matsumura, "Small crack property of austenitic stainless steel with artificial corrosion pit in long life regime of fatigue," International Journal of Fatigue, vol. 28, no. 11, pp. 1603-1610, 2006.

[13] S. A. Shipilov, "Solving some key failure analysis problems using advanced methods for materials testing," Engineering Failure Analysis, vol. 14, no. 8, pp. 1550-1573, 2007. 

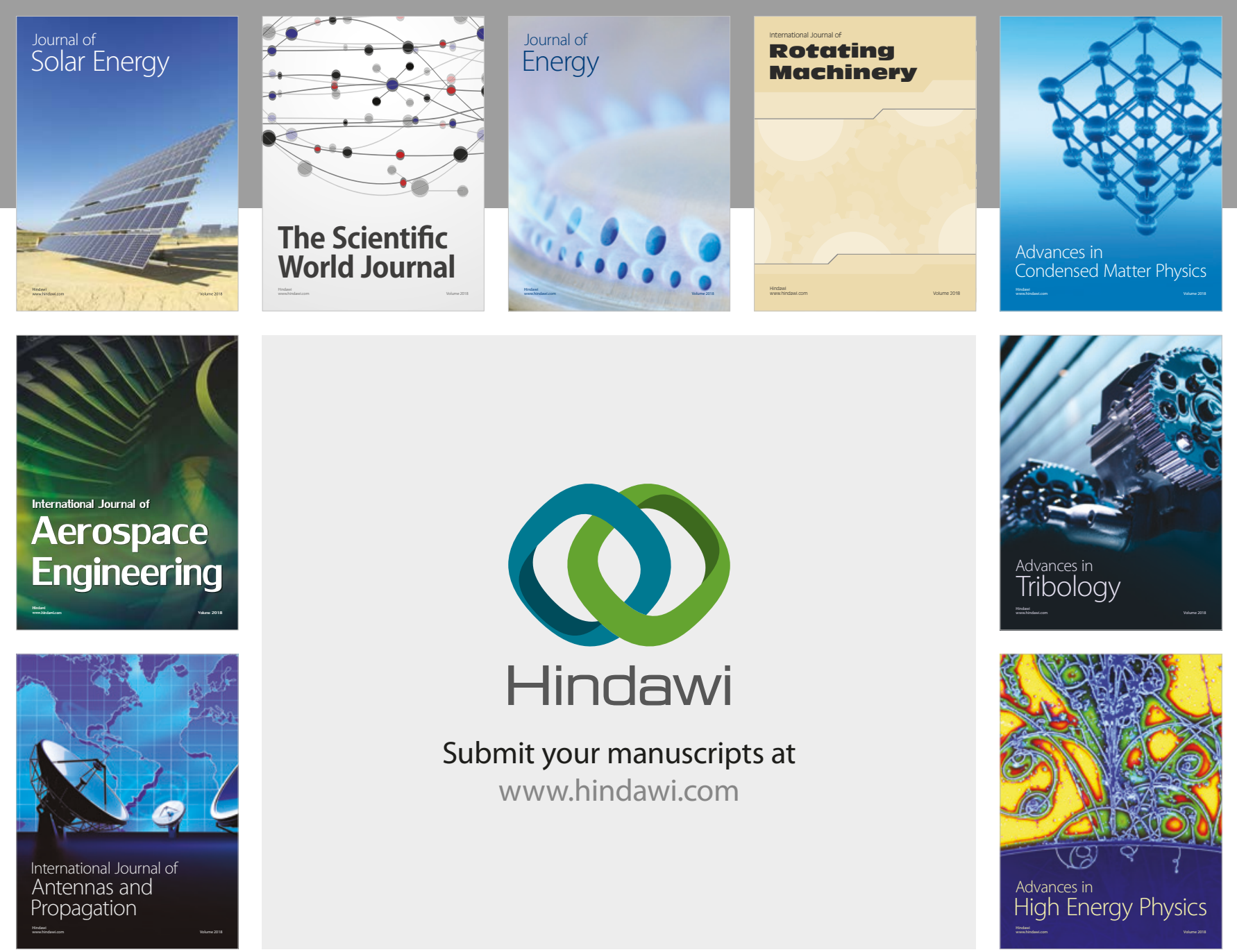

Submit your manuscripts at

www.hindawi.com
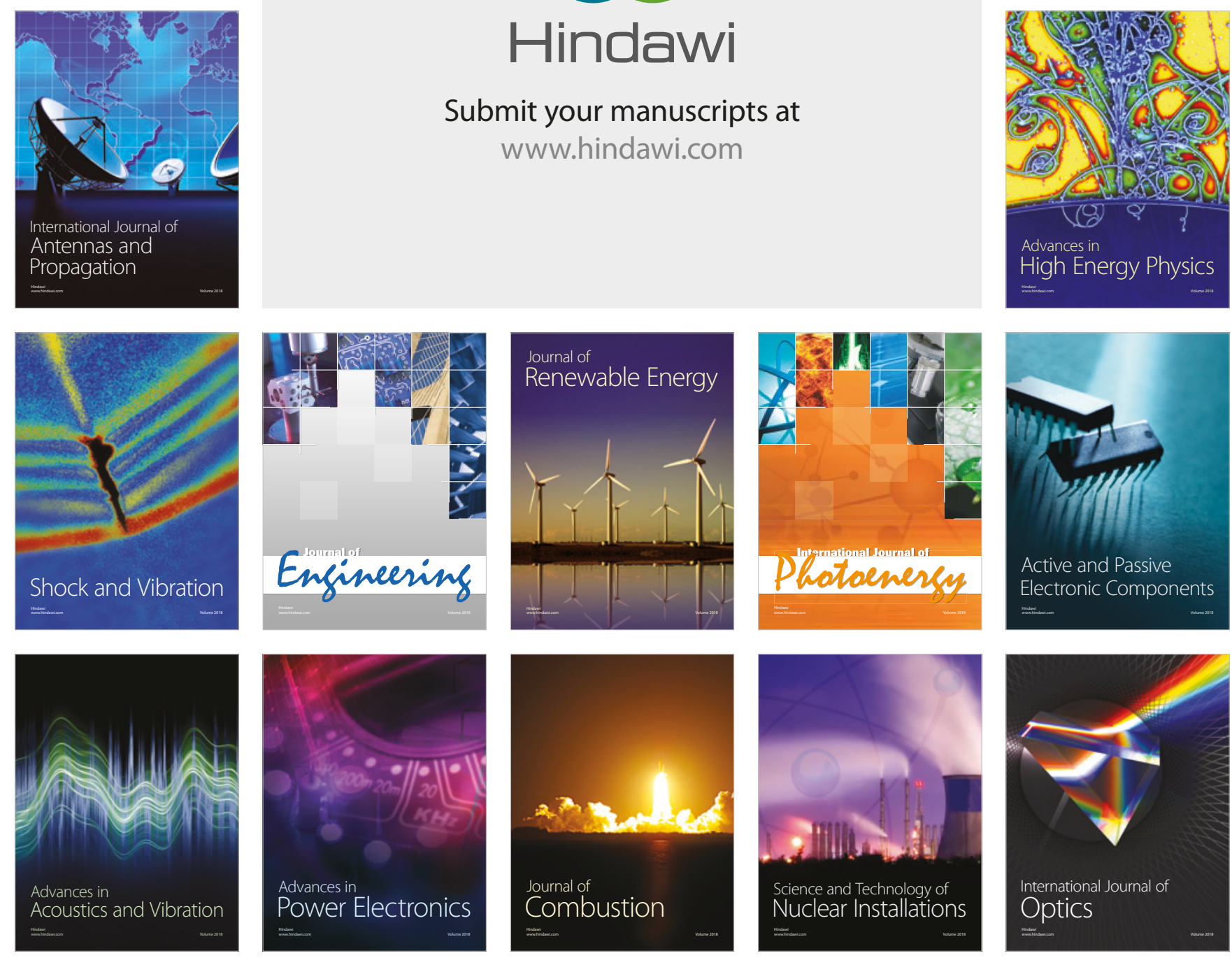